\title{
INTEGRATED ANALYSIS AND TOOLS FOR LAND SUBSIDENCE SURVEYING AND MONITORING: A SEMI-QUANTITATIVE APPROACH
}

\author{
A. Mosconi ${ }^{\text {a }}$, A. Pozzoli ${ }^{\text {a }}$ A. Meroni ${ }^{\text {b }}$, S. Gagliano ${ }^{\text {b }}$ \\ ${ }^{a}$ Eni S.p.a., Geodynamic Dept., via Maritano 26, 20097 San Donato Milanese, Italy - (alice.pozzoli, alessandro.mosconi)@eni.com \\ b Exelis VIS, Viale Colleoni 25, 20864 Agrate Brianza MB, Italy - (alberto.meroni, stefano.gagliano)@exelisvis.com
}

KEY WORDS: Oil\&Gas, Surveying, Geodynamics, SAR, CGPS, piezometers, assestimeters, integrated analysis

\begin{abstract}
:
This paper presents an integrated approach for land subsidence monitoring using measures coming from different sensors. Eni S.p.A., the main Italian oil and gas company, constantly surveys the land with all the state of the art and innovative techniques, and a method able to integrate the results is an important and actual topic. Nowadays the world is a multi-sensor platform, and measure integration is strictly necessary. Combining the different data sources should be done in a clever way, taking advantages from the best performances of each technique. An integrated analysis allows the interpretation of simultaneous temporal series of data, coming from different sources, and try to separate subsidence contributions. With this purpose Exelis VIS in collaboration with Eni S.p.A. customize PISAV (Permanent Interferometric Scatterometer Analysis and Visualization), an ENVI extension able to capitalize on and combine all the different data collected in the surveys. In this article are presented some significant examples to show the potential of this tool in oil and gas activity: a hydrocarbon storage field where the comparison between SAR and production volumes emphasise a correlation between the two measures in few steps; and a hydrocarbon production field with the Satellite Survey Unit (S.S.U.), where SAR, CGPS, piezometers and assestimeters measure in the same area at the same time, giving the opportunity to analyse data contextually. In the integrated analysis performed with PISAV not always a mathematical rigorous study is possible, and a semi-quantitative approach is the only method for results interpretation. As a result, in the first test case strong correlation between injected hydrocarbon volume and vertical displacement were highlighted; in the second one the integrated analysis has different advantages in monitoring the land subsidence: permits a first qualitative "differentiation" of the natural and anthropic component of subsidence, and also gives more reliability and coverage to each measurement, taking advantages from the strong points of each technique.
\end{abstract}

\section{INTRODUCTION}

Land subsidence represents a complex phenomenon due to natural and anthropic causes. Natural component is the results of geological and geodynamic processes occurring both at regional and local scale (Johnson, 1995). It can be investigated by using appropriate data which belong to different geo-science disciplines (i.e. geology, geodynamics, geophysics, geodesy, climate, etc.). Measurements of these processes can be done on the terrestrial surface and subsurface by using innovative and traditional technologies (GPS, satellite survey, assestimeter, piezometer, topographic and bathymetric surveys, microseismicity, etc.). Since monitoring means systematic sampling of selected variables in order to derive comprehension on phenomena dynamism and to take decisions respect to its effects, this activity appears fundamental in the management of environmental problems. A clever integration of the different measurements is strictly necessary. The aim of this paper is to present the potentialities of an integrated analysis that thanks to PISAV (Permanent Interferometric Scatterometer Analysis and Visualization), an ENVI extension, helps the surveyors to monitor land subsidence by a semi-quantitative approach. It is not easy to estimate quantitatively the anthropogenic component of subsidence so it is possible to give a first "qualitative" differentiation of the natural and anthropic components with statistical methods.

The present-day vertical velocity of an area $\left(V_{t o t}\right)$, with respect to the mean sea level, is the combination of different components (see equation 1 ).

$$
V_{\text {tot }}=V_{t}+V_{g l}+V_{c}+V_{p g y}+V_{\alpha}
$$

$$
\text { where } \quad \begin{aligned}
& V_{t o t}=\text { Present-day vertical velocity } \\
& V_{t}=\text { Tectonic component } \\
& V_{s l}=\text { Sedimentary load component } \\
& V_{c}=\text { Compaction component } \\
& V_{p g r}=\text { Post-glacial component } \\
& V_{a}=\text { Anthropic activity }
\end{aligned}
$$

Negative velocity indicates subsidence while positive velocity uplift. $V_{t}, V_{s l}$, and $V_{c}$, respectively tectonic, sedimentary and compaction components have long term geological effects (millions of years); $V_{p g r}$, post-glacial component is a short term geological component (thousands of years). The sum of these four factors accounts for the natural component of vertical movement. $V_{a}$ is the anthropogenic component of vertical motion, and it has a very short term effect (Carminati, 1999). The evaluation of the anthropogenic component is a very important point for land subsidence estimation, and nowadays only an integrated approach could reach this goal. Hence, for all the above mentioned causes, the geodynamic process has to be considered carefully to explain the observed vertical crustal deformation.

Part of the subsidence at ground level is sometimes caused by the compaction of the reservoir rock due to hydrocarbon extraction. The spatial and temporal development of subsidence is dependent on the production rate, the physical reservoir rock properties and the overlying subsurface layers (Keteelar, 2009). Environmental effects caused by hydrocarbon production and virtuous ethical behaviour make the distinction between natural and anthropic components inside measurements suitable. Moreover this knowledge can better drive the production choices. Surveying the activities in the oil\&gas industry became 
a primary task to consider. Many sensors are used to measure and monitor all the different and possible risks, and a wide data base needs a powerful and specifically designed tool able to visualize and analyse all the data taking advantage of each technique. PISAV is the specific tool developed for this purpose.

In the case of monitoring the vertical crustal deformation due to natural or anthropic causes, millimetric vertical resolution is required. Therefore, the spatial resolution requirements cannot be economically satisfied using the current GPS techniques alone (Linlin, 2001). Synthetic Aperture Radar (SAR) provides a deformation image on a pixel-by-pixel basis over an area of thousands of square kilometers (Stein A., 2004). Thanks to modern algorithms SAR monitoring is able to reach millimetric accuracy in displacement velocity measures (Ferretti, 2007), but it is a relative movment. To have an absolute displacement it is necessary to calibrate the SAR image with georeferenced and accurate measure, like as Continuous GPS (CGPS).

An integrated analysis allows to improve coverage, accuracy and reliability of the results. The integration with different sensors and measures (like as rainmeter, termometer, social index, etc.) could also help with correct planning land management activities in order to reduce the effects of subsidence in historical cities and industrial zones (Baldi, 2009).

\section{MONITORING SYSTEMS}

Eni S.p.A., the main Italian oil and gas company, uses the most advanced techniques for vertical displacement monitoring. A constant update of the technologies is done. An integrated approach is the only one that permits to have high accuracy and reliability data for a solid interpretation and analysis of the results, particularly dealing with small displacements usually measured. A well-made plan for land subsidence surveying is able to handle the environmental effect connected to hydrocarbon extraction.

To distinguish between anthropic land subsidence caused by hydrocarbon extraction and natural land subsidence or caused by water extraction it is necessary to:

1. survey an area wide enough, around the hydrocarbon field, to include possible secondary effects

2. measure shallow soil consolidation in water extraction areas

3. monitoring vertical displacement before the beginning of hydrocarbon activities and some years after the well shutdown

This last point is very important, in fact after the well shutdown some residuals land subsidence or some rebound effects could occur.

In 2011 Italian government sets precise and strict specifications about subsidence phenomena for a sustainable development of hydrocarbon fields. Since then all the monitoring techniques in Eni S.p.A. follow these guidelines for the correct execution of the measures and for the right validation of the results (Gambolati, 2011).

In the following sections some of the most used surveying techniques are described, with a focus to vertical displacement monitoring.

\subsection{Levelling}

Levelling is the traditional technique for vertical variation measurement. It is used from more than 100 years and it is still the most accurate technique for this purpose. The levelling network should have a specific number of benchmarks proportional to the extension (at least every one kilometer) of the area. To have accurate and absolute measures it is necessary to connect the local network to a national geodetic vertical one (Schomaker, 1981). The main problem of levelling network for wide regions is the long distances to survey: this condition extends the time for the survey (till some months) and introduces a high standard deviation error even with frequently known coordinate benchmark adjusting.

A comparison between levelling and SAR data, even if it shows a theoretical coherence in the results, it is only an academic exercise because of the lack of samples in levelling measures, not adequate to be compared to the SAR sampling, which is denser.

\subsection{GPS}

Nowadays continuous GPS are the most popular technique to detect displacement with good accuracy. CGPS could measure only some spot points, so the need to choose some major points where to install the GPS. CGPS should be connected to an international network (actually in use ITRF2008 Igb08) and should measure at the same time as at least 4 CGPS of the international network.

Due to the noise in the vertical component rough land subsidence estimation is done with at least 12 months of measures. Even if 36 months are the common accepted limit by the scientific community to eliminate middle and long term periodical effect in the signal (Blewitt, 2002).

\subsection{SAR}

SAR is well known as surveying technique for subsidence monitoring. Temporal update is much more frequent than levelling measurements (Ketelaar, 2009), and spatial coverage is able to provide information on a wider area than with levelling or GPS measurements. Eni S.p.A. uses the interferometric temporal series on single permanent scatterers or diffuse scatterers (Ferretti, 2001).

To improve reliability and to get absolute results it is necessary to combine the interferometric data collected with another complementary geodetic measurement technique, such as the CGPS.

\subsection{Assestimeters and Piezometers}

Assestimeter can calculate natural compaction of the shallower portion of sedimentary coverage and distinguish the compaction related to water extraction. The method is based on measurement of the movement between an anchor weight in depth and the surface. Figure 1 shows a schematic of an assestimeter. Two different moments of measurement are presented, on the left before a vertical displacement occurs, and on the right after a vertical motion appears. 


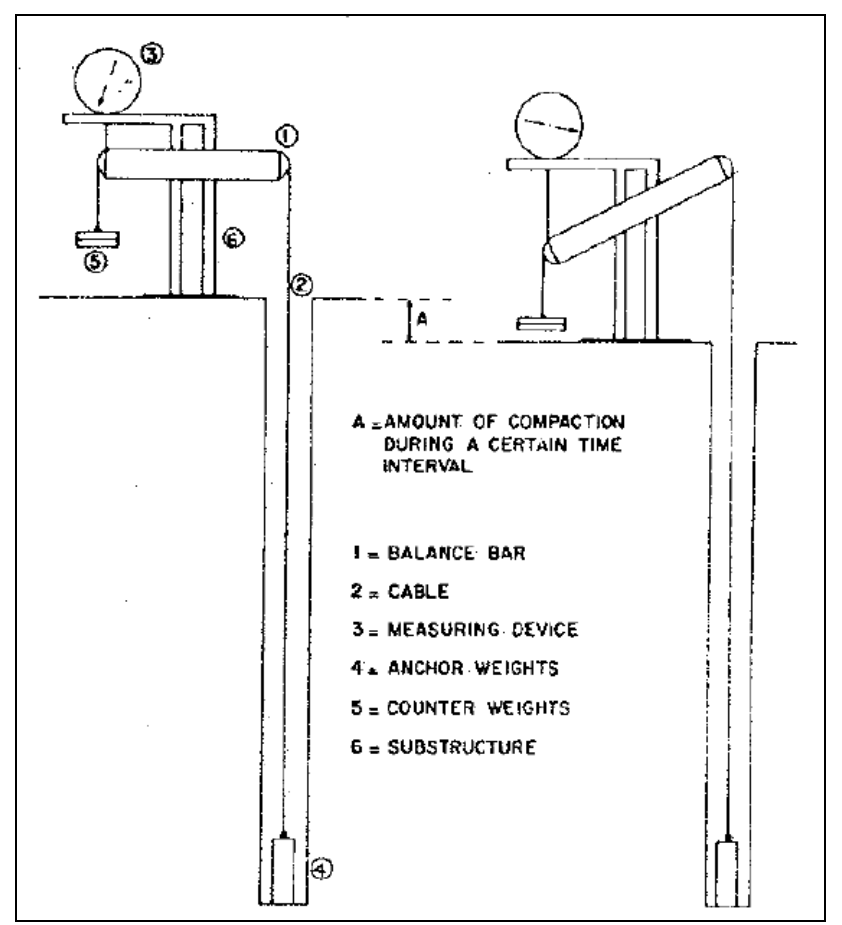

Figure 1. Assestimeter, Cable-measurement method

Piezometer instead is used to measure:

1. $\quad$ static liquid pressure in a system by measuring height to which a column of the liquid rises against gravity

2. the static pressure (piezometric head) of groundwater at a specific point

A scheme of a piezometer is shown in Figure 2.

Pressure can be read manually or automatically, by using electrical pressure transducers.

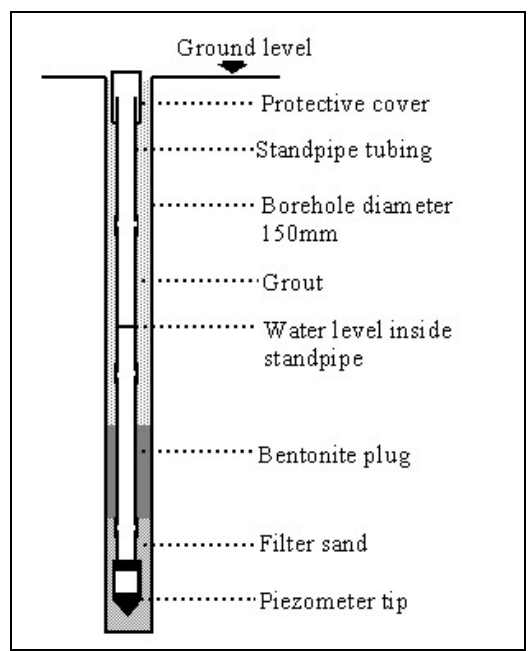

Figure 2. Scheme of borehole and piezometer

Assestimeters and piezometers should be installed contemporaneously in the same area. Piezometers define the aquifer with higher depletion and his compaction, and combined with the assestimeter vertical displacement measure, is a powerful tool to control the flow rate, the compaction entity and finally the total subsidence.

\section{INTEGRATED ANALYSIS}

In our experience an integrated analysis is required to have the best performance from the surveying techniques. An individual analysis of the results could not show the real behaviour of the studied area (Mussio, 2000). In the following sections we show some examples of data and analysis integration. SAR and GPS data are the most common data to integrate, taking advantage from accuracy of GPS and coverage of SAR data; in a second step the analysis of assestimeter and piezometer measures could be really useful to go deeper in the study of the causes of land compaction and soil sinking. All the measures are in-house collected data, except for SAR images. Eni S.p.A. uses to begin monitoring activity before hydrocarbon production starts, and extends it for a few years after the end of the field life.

In sections 5 and 6 are presented two typical activities very common in oil and gas industry to show the potential of an integrated analysis: a hydrocarbon storage field where the comparison between SAR and production volumes emphasise a correlation between the two measures in few steps; and the Satellite Survey Unit (S.S.U.) in a hydrocarbon production field, where SAR, CGPS, piezometers and assestimeters measure in the same area at the same time, activating the possibility to analyse data contextually.

In this phase of the project only qualitative and semiquantitative considerations could be done, but the software PISAV with quick operations give at a glance a solid tool for an integrated interpretation of the data to be compared with predicting subsidence models available (not discussed in this paper).

In the following sections we will treat ground displacements and not velocities, due to the direct analysis of measured data. A velocity is always computable in a specific period.

\section{PISAV (PERMANENT INTERFEROMETRIC SCATTEROMETER ANALYSIS AND VISUALIZATION)}

In collaboration with Eni S.p.A., Exelis VIS customized PISAV, an ENVI extension able to combine and capitalize on all the data collected in different surveys. By applying signal processing techniques, PISAV allows the spatial and multitemporal analysis of the sampled data, with the aim of removing the components which are generated by natural causes. These can be, for instance, changes in temperature or in ground elevation due to tectonic subsidence or bradyseism phenomena.

To this end, further analyses can be performed by means of classification and clustering algorithms which are implemented in additional tools. All the analytical tools are integrated and handled through a highly interactive application that allows also the data visualization in 2D, 3D and 4D (i.e. time animations).

\section{HYDROCARBON STORAGE FIELD}

\subsection{Test Area}

The studied area is a hydrocarbon storage field in Italy, where hydrocarbon can be stored for an indefinite period of time for later consumption. Storage fields are characterized by withdrawal and injection cycles, whose period depends on many factors like as energy needs, economical sustainability, injection 
capacity, etc. All the hydrocarbon storage fields in Italy are surveyed and analysed as the test case described in this section.

A very focal point is the study of vertical displacements, for that purpose SAR data are analysed to monitor wide area behaviour. In Figure 3 it is shown the velocity map, where negative values (red) indicate subsidence areas, while positive values (violet) shows uplift.

The data processing permits to study altimetric variations related to withdrawal and injection cycles. In hydrocarbon storage fields withdrawal and injection cycles have seasonal periodicity mainly due to hydrocarbon demand: in winter grows and during the summer decrease.

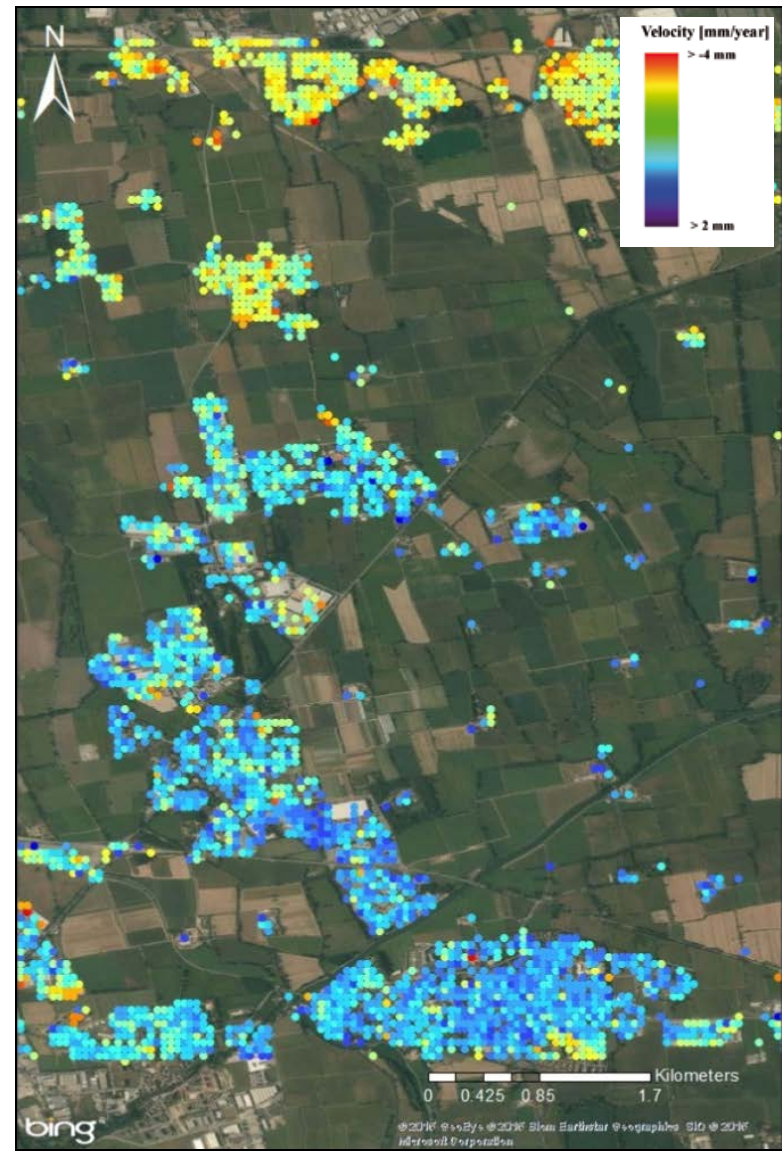

Figure 3. Permanent scatterers in the test area

\subsection{Integrated analysis workflow}

Eni S.p.A. periodically collects and analyse SAR data to monitor possible ground displacement, in particular long temporal series of interferometric SAR images.

Time series helps to have a general view on the regional behaviour of the territory.

Eni S.p.A. has developed a specific procedure for the integrated analysis in storage field monitoring, and PISAV help the surveyor to integrate data and to analyse possible correlations, relations and interactions of different phenomena. The procedure processes vertical displacements coming from SAR data and permits to remove the subsidence regional behaviour, as a result a comparison with injection activity curve is possible, and a correlation analysis is done.
The procedure is described more in details in the following subsections.

\subsubsection{Fast best fit}

A polynomial regression is done, taking into account all the points of the area. The result is the best fitting interpolation curve for the entire scene. The selected area should be larger enough to include a regional behaviour.

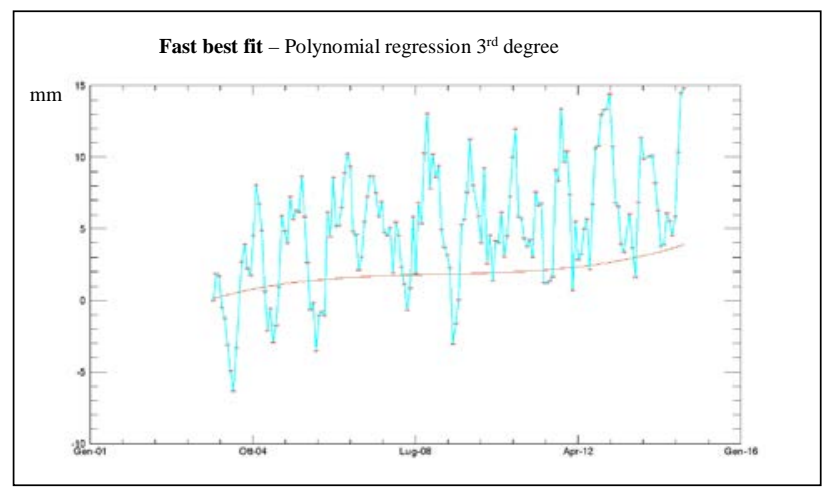

Figure 4. Polynomial interpolation ( $3^{\text {th }}$ degree) of the area (red) and vertical displacement temporal series of a point inside the storage field (light blue)

\subsubsection{Residual curve}

The altimetric residual curve was computed on the whole scene. In Figure 5 it is shown the residual curve deriving from the subtraction of the fast best fit calculated curve from the vertical displacement temporal series of a point inside the storage field. With this operation we try to filter a regional component of land subsidence from the signal. The Regional component is intended to be a constant subsidence velocity present in the overall area, surely not caused by anthropic activity.

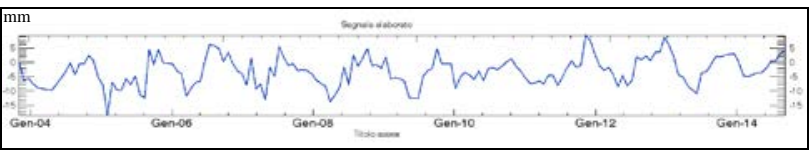

Figure 5. Residual curve of a point inside the storage field

\subsubsection{Frequency component}

To find a periodic behaviour a computation of a frequency component is calculate with a Fast Fourier Transform algorithm. In the plot of Figure 6 occurrence of different frequencies of the residual curve are presented. The result shows a periodicity around one year, corresponding with a typical storage field cycle (injection during warm seasons, withdrawal during cold ones). With this step we are able to remove the seasonal behaviour.

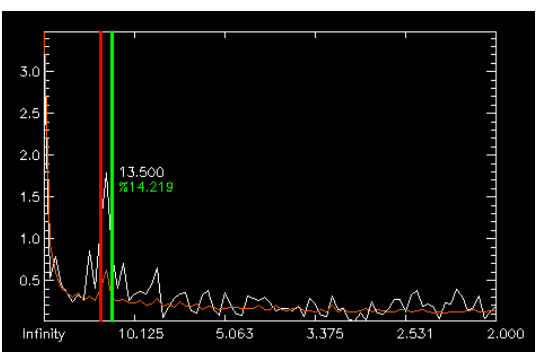

Figure 6. FTT analysis 
In the pie chart of Figure 7 it is also possible to visualize the results of the band-pass filter of Figure 6 as percentage, having an immediate view on the periodic behaviour of the time series.

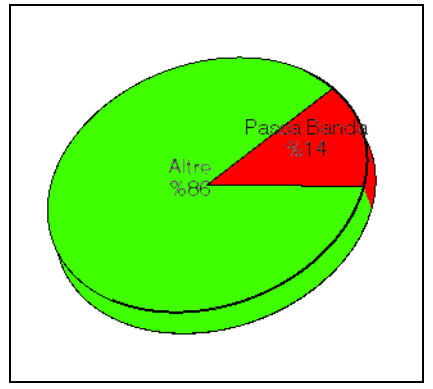

Figure 7. Pie chart of low-pass filter frequencies

\subsubsection{Comparison with production curve}

At this point of the procedure a comparison with the production curve of the storage field is done. The comparison shows a correlation between withdrawal/injection cycles and subsidence/rebound movements, as shown in Figure 8. We register a negative displacement (subsidence) during withdrawal period, while a rebound effects is measured during injection periods.

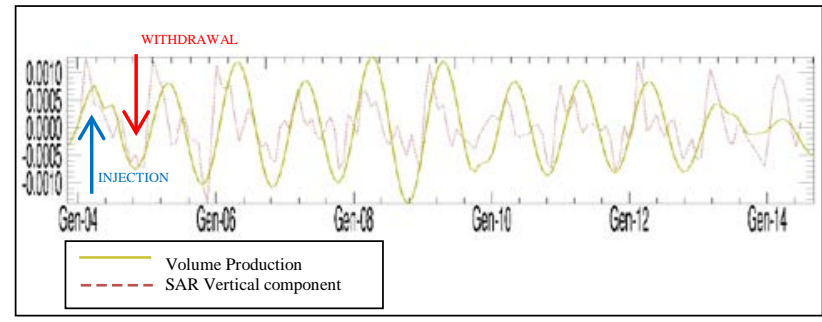

Figure 8. SAR time series (vertical component) compared with volume production (blue arrow: injection and rebound, red arrow: withdrawal and land subsidence)

\subsubsection{Qualitative Cross-correlation}

A qualitative cross-correlation between the second order derivative curves of ground movement (up or down) and injection activity (storage or consumption) is computed. This is not a rigorous cross-correlation algorithm, it is a statistic evaluation of the number of points with the coherent cause and effect behaviour (injection vs. uplift in the $1^{\text {st }}$ quadrant, withdrawal vs. subsidence in the $3^{\text {rd }}$ one). The coherence value is computed as correlated point respect to the total number of points. In Figure 9 it is possible to see the qualitative crosscorrelation plot with different time shift (1, 2, 3 months) between the two curves. Normally a short inaertia of 1-3 months can been detected between injection activity and ground response. In the presented case the response of the surface level has a delay of 2 months, with a coherence value of $66,7 \%$.

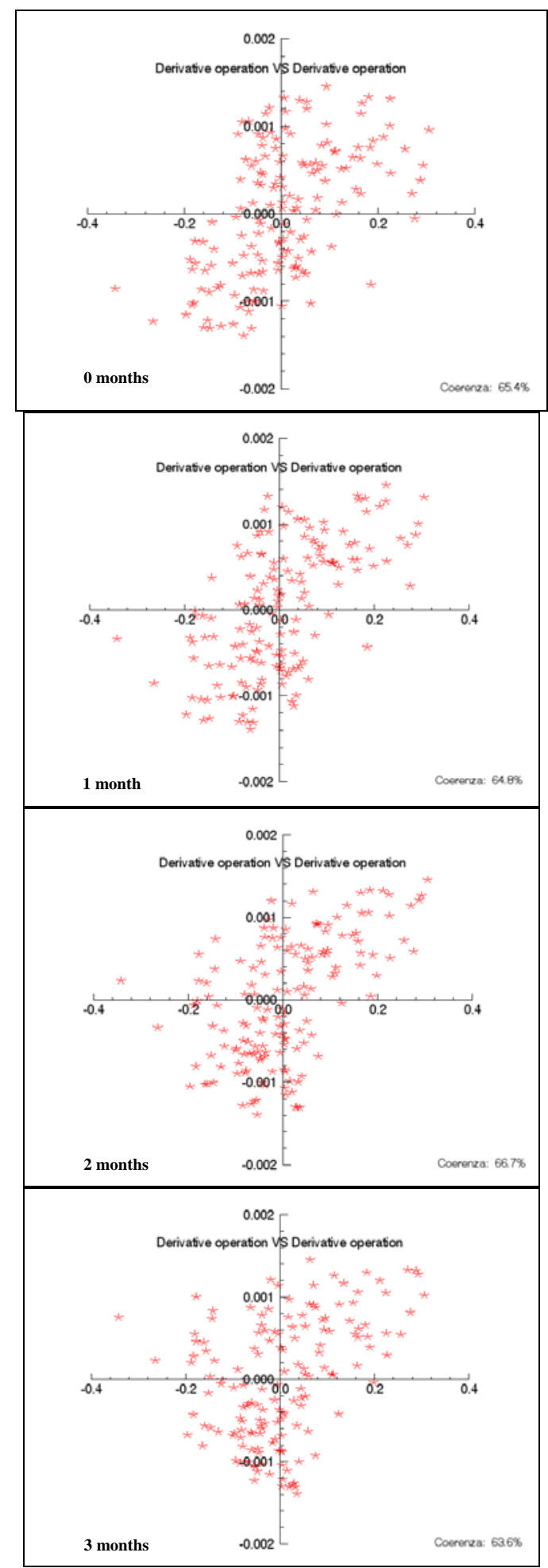

Figure 9. Qualitative cross-correlation between ground movement (up or down) and injection activity (storage or consumption)

\subsection{Results}

The knowledge of a correlation between ground movement and injection activity, and its inertia shift, considering that the vertical displacement could be mainly due to the injection activity, advise the company in the management of maximum injection volume and pressures. 


\section{HYDROCARBON PRODUCTION FIELD AND THE SATELLITE SURVEY UNIT (S.S.U.)}

\subsection{S.S.U. (Satellite Survey Unit)}

In 2001 eni S.p.A. started the conception of a surveying system able to collect measures from different techniques in the same point. In 2005 the first Satellite Survey Unit was installed. The S.S.U. combine two corner reflectors for SAR data, a Continuous GPS station and a levelling benchmark as shown in Figure 10. In Figure 11 is possible to see the S.S.U. response in a SAR amplitude image. In Figure 11-B is visible the bright response after the corner reflectors installation.

Where is possible, in addition to these three surveying technologies, there are at least one assestimeter and two or more piezometers depending on the criticality and morphological configuration of the area, and the aquifers type and usage.

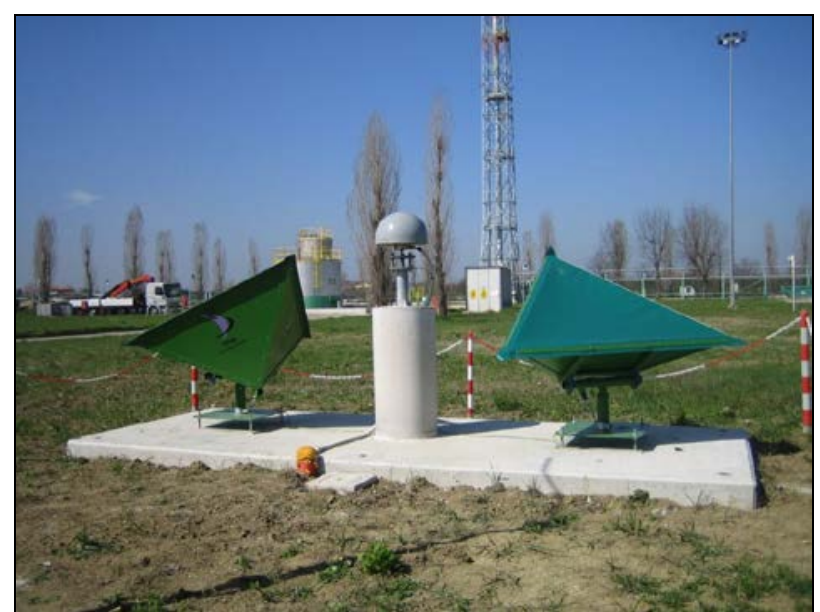

Figure 10. Satellite Survey Unit (S.S.U.)
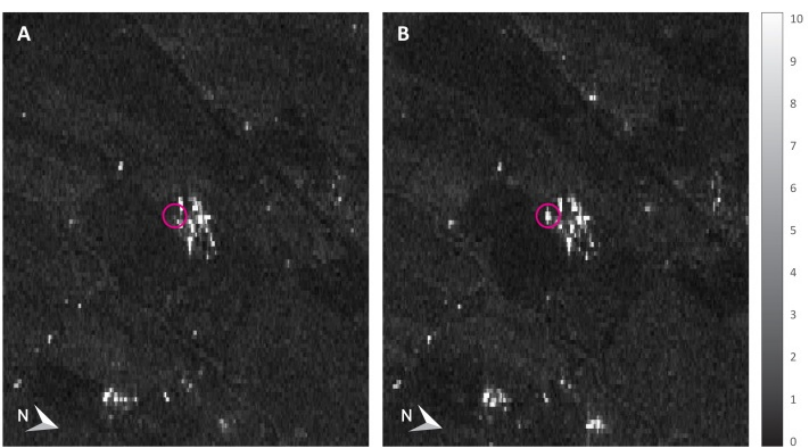

Figure 11. SAR Amplitude Image, S.S.U. response. On the left before the corner reflectors installation, on the right after corner reflectors installation

\subsection{Surveying Data and integrated analysis}

The S.S.U. permits to have contemporary measures with known relative position, simplifying the integration among the different surveying techniques. In Figure 12 a screenshot of PISAV compares temporal series with the same period of different monitoring systems. In Figure 13 with a normalized plot of GPS, SAR vertical component and assestimeter data, is possible to give a first interpretation of the phenomena on the test area.
A first calibration of the SAR data with GPS data is required. Some different algorithms are used depending on the characteristics of the area, and the number of CGPS installed. CGPS velocity is used to calibrate SAR images, in such a way that SAR measure could be compared with other measures with an approximation.

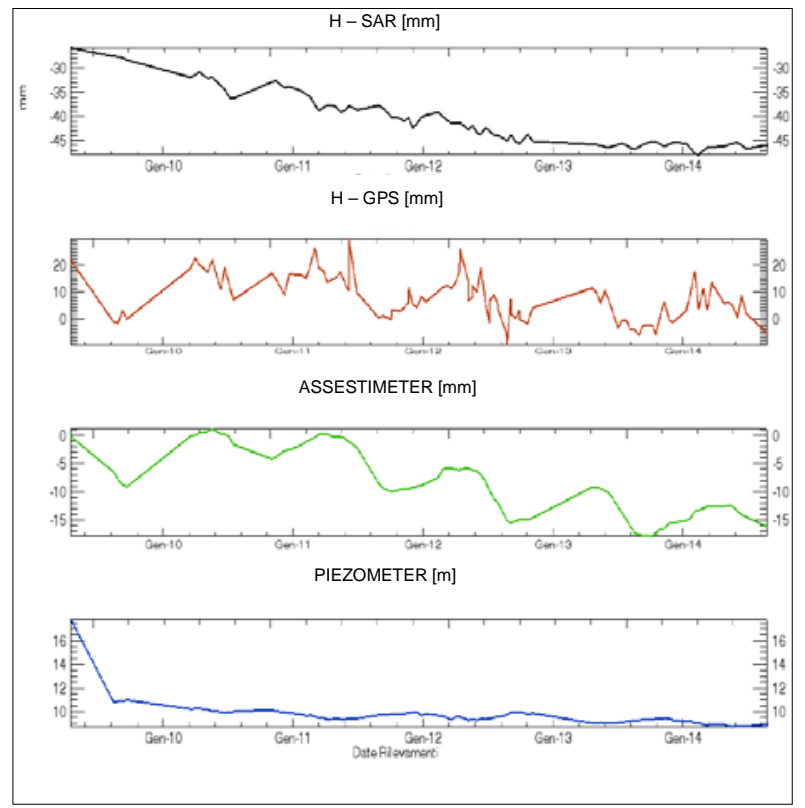

Figure 12. S.S.U. (SAR, CGPS), assestimeter and piezometer measures

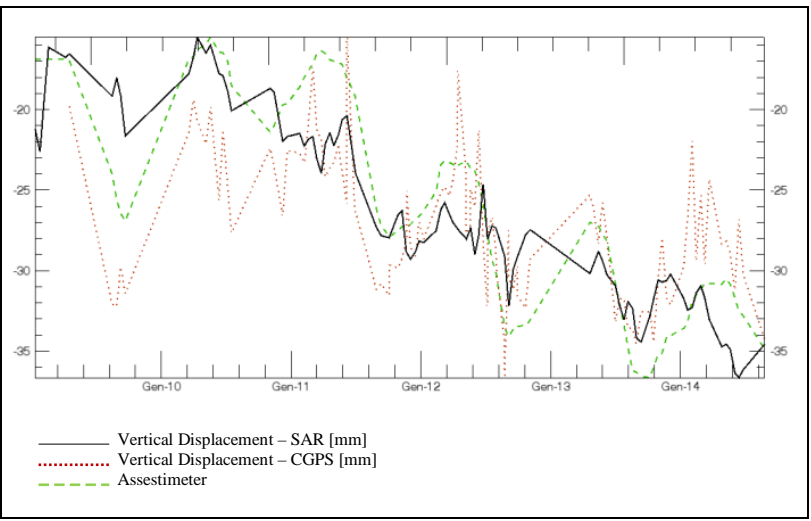

Figure 13. Normalized overplot among the time series of the assestimeter, CGPS and SAR vertical component measures

Superficial assestimeter is able to measure the land subsidence mainly due to water withdrawal and superficial compaction. Integrate this measure in PISAV with SAR or CGPS time series gives qualitative information about land subsidence not caused by water withdrawal.

A possible analysis is to compute a difference between the linear interpolation of SAR data and the one of the superficial assestimeter. The difference between the two interpolation curves gives an idea of the residual land subsidence magnitude (see Figure 14). If the point is chosen in a strategic area (generally a stable area outside the hydrocarbon field) this difference is near to a regional behaviour of vertical ground displacement. 


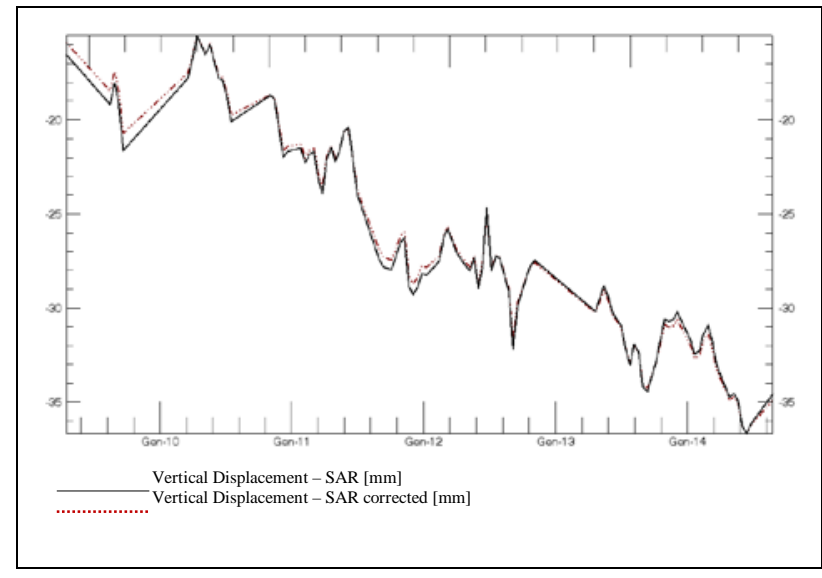

Figure 14. SAR vertical component corrected with a regional component of land subsidence.

\subsection{Results}

The concurrence of different sensor measures permit the estimation of a water withdrawal and superficial compaction and if the point are suitable chosen could also estimate the entity of a regional component of subsidence, not attributed to production activity.

\section{CONCLUSIONS}

In oil and gas activity, ground displacement monitoring is an important issue to constantly survey. The measure integration improves coverage, accuracy and reliability of the results.

An integrated analysis gives a wider view on the phenomena in the area of interest. The large quantity of different surveying techniques produce a very huge amount of data and a tool for the visualization and interpretation of data is strictly needed.

PISAV is a versatile and incremental tool, able to help the interpreter to have a control on the whole area (and not only on some interesting points).

PISAV is a commercial software distributed by Exelis VIS, and it is a tool in continuous upgrading accordingly with the needs of land subsidence monitoring.

\section{REFERENCES}

Baldi, P., Casula, G., Cenni, N., et al., 2009. GPS-based monitoring of land subsidence in the Po Plain (Northern Italy). Elsevier, Earth and Planetary Science Letters 288, pp. 204-212.

Blewitt, G. and Lavallée, D., (2002). Effect of annual signals on geodetic velocity. In: Journal of Geophysical Research, 107(B7), 2145, pp. ETG 9-1-ETG 9-11.

Carminati, E., Di Donato, G., 1999. Separating natural and anthropogenic vertical movements in fast subsiding areas: the Po plain (N. Italy) case. Geophysical Research Letters, 26(15), pp. 2291-2294.

Ferretti, A., Prati, C., Rocca, F., 2001. Permanent scatterers in SAR interferometry. IEEE Transaction Geoscience and Remote Sensing, 39, pp. 8-20.

Ferretti, A., Savio, G., Barzaghi, R., Borghi, A., 2007. Submillimeter Accuracy of InSAR Time Series: Experimental
Validation. IEEE Transactions on Geoscience and Remote Sensing, 45(5), Pp. 1142 - 1153.

Gambolati, G., Teatini, P., Ferronato, M., 2007. Linee Guida per lo Studio dei Fenomeni di Subsidenza nell'Ambito di Progetti di Sviluppo Sostenibile di Campi ad Olio e Gas. Rapporto Tecnico 1/2007 of DMMMSA, Univ. of Padova (Italy).

Johnson, A. I., 1991. Land Subsidence. In: International Association of Hydrologicas Sciences, Huston, Texas, No.200.

Ketelaar, V.B.H.G., 2009. Satellite Radar Interferometry, Subsidence Monitoring Techniques. Remote Sensing and Digital Image Processing, Springer Verlag, 14, pp.7-26.

Linlin, GE, Horgne-Yue, C., Shaowei, H., Rizos, C., 2001. Integrated GPS And Interferometric SAR Techniques For Highly Dense Crustal Deformation Monitoring. In: Proceedings of the 14th International Technical Meeting of the Satellite Division of The Institute of Navigation (ION GPS 2001), Salt Lake City, UT, pp. 2552-2563.

Mussio, L., Giacobbe, L., Bellone, T., 2000. Processing of Correlated Information. In: International Archives of Photogrammetry and Remote Sensing, Amsterdam, The Nederlands, Vol.XXXIII, Part. B6, pp. 251-222.

Schomaker, M.C. \& Berry, R.M., 1981. Geodetic Leveling, NOAA Manual NOS NGS 3.

Stein, A., Zhou, Y., 2004. Use of geostatistics to integrate interferometric SAR data with leveling measurements of land Subsidence. In: The International Archives of the Photogrammetry, Remote Sensing and Spatial Information Sciences, Istanbul, Turkey, Vol. XXXV, Part B2, pp. 581-585. 